\title{
Effects of arousal on human visual dominance
}

\author{
KIMRON L. SHAPIRO \\ University of Calgary, Calgary, Alberta, Canada \\ BARBABA EGERMAN \\ Cornell University, Ithaca, New York \\ and \\ RAYMOND M. KLEIN \\ Dalhousie University, Halifax, Nova Scotia, Canada
}

\begin{abstract}
Human attention research has found that vision controls attention when competing against other sensory modalities, for example, audition, proprioception, taction. Similarly, animal learning experiments have demonstrated visual attentional control when animals are positively motivated but auditory control when aversively motivated. The experiments with animals suggest a way of attenuating visual dominance in humans. Three experiments using human subjects explored the degree of visual versus auditory control exhibited in the presence of different arousal states. In Experiments 1 and 2, an electric shock and a threat of electric shock, respectively, to the subject's finger resulted in auditory attentional control. In Experiment 3, a tactile stimulus resulted in attenuated visual control. The results of these experiments are discussed in relation to the evolutionary advantage conferred by such attentional strategies.
\end{abstract}

In recent years, there have been a considerable number of demonstrations that visual stimuli are prepotent in situations in which vision is competing for attention with other sensory modalities. This prepotence has been referred to as visual dominance. Vision has been shown to dominate over audition (Colavita, 1974; Colavita \& Weisburg, 1979; Egeth \& Sager, 1977), over proprioception (Pick, Warren \& Hay, 1969), and over taction (Gibson, 1933; Rock \& Victor, 1964). The present research report focuses on the relationship between vision and audition.

Findings of visual dominance have persisted in spite of various attempts to attenuate such dominance. In a series of experiments, Colavita (1974) presented subjects with a series of single-stimulus trials in which they were exposed to either a tone or an incandescent light bulb. Subjects were required to respond to stimulus onset as quickly as possible by depressing one of two keys corresponding to tone and light, respectively. On a small number of "conflict" trials embedded in single-stimulus trials, subjects were presented with the tone and light simul-

I want to thank Vin LoLordo and Jane Raymond for a careful reading of the manuscript. Paul Cornwell at The Pennsylvania State University is thanked for providing the space and equipment with which this research was accomplished. Jerry Devins at the University of Calgary is thanked for carefully proofreading the manuscript. The author was at The Pennsylvania State University when this research was performed. Requests for reprints should be addressed to Kimron Shapiro, Department of Psychology, University of Calgary, 2500 University Drive N.W., Calgary, Alberta, Canada T2N 1N4. taneously. They were "deceived" into believing these trials were accidental and were given no instructions as to how to respond. The subjects' choice of tone or light on "conflict" trials constituted the behavior of interest. In the first experiment, the subjects matched the tone and light for subjective intensity before beginning the series of single-stimulus and "conflict" trials described above. On 49 of the 50 "conflict" trials across subjects, responding was to the visual stimulus with most subjects failing to detect even the presence of the auditory stimulus.

Subsequent experiments designed to explore the relationship of stimulus intensity to sensory dominance included both increasing the subjective intensity of the tone relative to that of the light and decreasing visual stimulus salience relative to background illumination. Neither of these manipulations was successful in reducing visual dominance. Moreover, informing subjects of the possibility of "conflict" trials and instructing them to respond to the stimulus first perceived did not attenuate visual dominance either. The only manipulation successfully reducing visual dominance was the explicit instruction to respond to the auditory stimulus on conflict trials. The results of Colavita's experiments suggest that visual dominance is mediated via a non-sensory (attentional) rather than a sensory (hard-wired) mechanism. This attentional mechanism has received support from the work of Colavita and Weisburg (1979), Egeth and Sager (1977), and Klein (1977).

Sensory dominance has been observed in experiments involving animals as well as humans (Foree \& 
LoLordo, 1973; Randich, Klein, \& LoLordo, 1978). More recently, Shapiro, Jacobs, and LoLordo (1980) explored the relationship of sensory dominance to appetitive and aversive reinforcers in both Pavlovian and operant conditioning paradigms. In the basic procedure, two groups of pigeons were repeatedly exposed to a compound stimulus consisting of a red light and a tone. In the appetitive group, the compound auditory-visual stimulus was paired with food, whereas in the aversive group, the compound was paired with electric shock. After repeated pairings, the stimulus elements comprising the compound were tested to determine which stimulus was controlling responding. In the group receiving food, the visual stimulus controlled responding, whereas in the group receiving electric shock, the auditory stimulus typically exhibited more control. The results of these and other experiments demonstrate what has been referred to in the animal learning literature as a constraint on learning. The use of the word "constraint" is meant to imply that some stimulus to event relationships are learned better (or, alternatively, faster) than others (see LoLordo, 1979, for a theoretical discussion of this issue). Although formally couched in both a different methodology and context, the experiments just cited are similar to the sensory dominance experiments previously discussed. These experiments demonstrate that visual stimuli are perceived more readily under certain conditions, whereas auditory stimuli are perceived more readily under other conditions.

\section{EXPERIMENT 1}

The results of the animal learning experiments discussed above have implications concerning a way of attenuating, if not reversing, the visual dominance found in humans. These experiments suggest that the presence of an arousing stimulus may result in auditory as opposed to visual dominance. The present experiment explored this possibility by using the same experimental procedure as Colavita (1974). In the Colavita replication groups, subjects were required to respond in a reaction time (RT) paradigm to either an auditory or a visual stimulus. On a relatively few "probe" trials, the auditory and visual stimuli were presented simultaneously and the variable of interest was to which stimulus subjects would respond first. Subjects in the experimental group were required to perform the same task but, upon responding, received a brief electric shock to one of their fingers on a predetermined number of randomly selected trials.

\section{Method}

Subjects. The subjects were 32 right-handed undergraduates who were naive to the present experiment. There were an equal number of males and females. All subjects were recruited ran- domly from an introductory psychology class. Each subject was then assigned randomly to a particular treatment group.

Apparatus. A two-channel tachistoscope connected to a Gerbrands " 300 " series millisecond timer and a Gerbrands lamp drive circuit presented the visual stimulus, which was a white 1.6-deg centrally located circular field. The auditory stimulus, a 65-dB $4000-\mathrm{Hz}$ pure tone, was presented binaurally through headphones. Both stimuli were presented for a maximum of $1 \mathrm{sec}$, after which the stimulus terminated automatically. Electric shock was delivered by a Farrall Instruments Mark I behavior modifier to the left index finger via two small silver electrodes held in place with an elastic band. Shock duration was programmed at $.5 \mathrm{sec}$, with shock intensity set by the subject.

The subject responded to either the auditory or the visual stimulus by depressing one of two buttons marked "tone" and "light," respectively, using the index and middle finger on his or her right hand. The stimulus terminated as soon as the correct response was made. RT was recorded to the nearest millisecond using a Hunter timer connected to the response panel. All programming, including stimulus presentations, was accomplished using standard electromechanical relay equipment.

Procedure. The subjects were assigned to either the shock (S) or no-shock (NS) treatment group, with both groups counterbalanced by sex and response-button position ("tone" button on either right or left side of "light" button). Before the experiment began, the subjects in the $S$ group set the shock level according to the instruction that the shock be "aversive, but not painful." The experimenter began with the lowest level of intensity and proceeded to higher intensities until the subject agreed that the criterion had been reached.

In the first part of the experiment, all subjects received 20 simple RT (practice) trials. On each trial, the subject was told which stimulus to expect. An equal number of auditory and visual trials were randomly presented. The subject was instructed to respond on the appropriate response key as quickly as possible, as soon as the stimulus was detected, without making mistakes. RTs were recorded for all trials.

Following simple RT trials, the subjects were presented with a series of 100 "choice"' RT trials. During "choice" RT trials, the subjects were not informed about which stimulus would be presented. On 80 of these trials, either the auditory or the visual stimulus was presented in a randomly alternating sequence (singlestimulus trials). The remaining 20 of the trials were combined auditory-visual trials composed of the two stimuli presented simultaneously (compound trials). Compound trials were embedded randomly throughout the 80 single-stimulus trials, with the restriction that no compound trials occur in succession. During this series of 100 "choice" trials, the subjects were instructed, as before, to respond on the appropriate response key as quickly as possible without making mistakes. On compound trials, the subjects were instructed to respond on the key corresponding to the stimulus first perceived. Responses on compound trials constituted the variable of interest.

Subjects in the $\mathrm{S}$ groups were given instructions identical to those just described, and told that they were to receive a shock immediately after responding if their RTs were either too slow or too fast. In actuality, these subjects received a shock immediately following the response on a randomly predetermined $20 \%$ of the 20 practice trials as well as on an equal percentage of the 80 singlestimulus trials. The subjects were shocked on an equal number of auditory and visual trials, and never shocked on compound trials.

The subjects were given a rest period midway through the "choice" trials for approximately $5 \mathrm{~min}$. At this time, the subjects in the $S$ groups were given a few "refresher" shocks and asked if the intensity still met the criterion set prior to the experiment. The shock intensity was adjusted, if necessary. All RTs and the stimulus chosen on compound trials were recorded for subjects in all conditions. Additionally, mean auditory and visual RTs on both simple and choice trials were computed, as was percent responding to both auditory and visual stimuli on compound trials. 
1

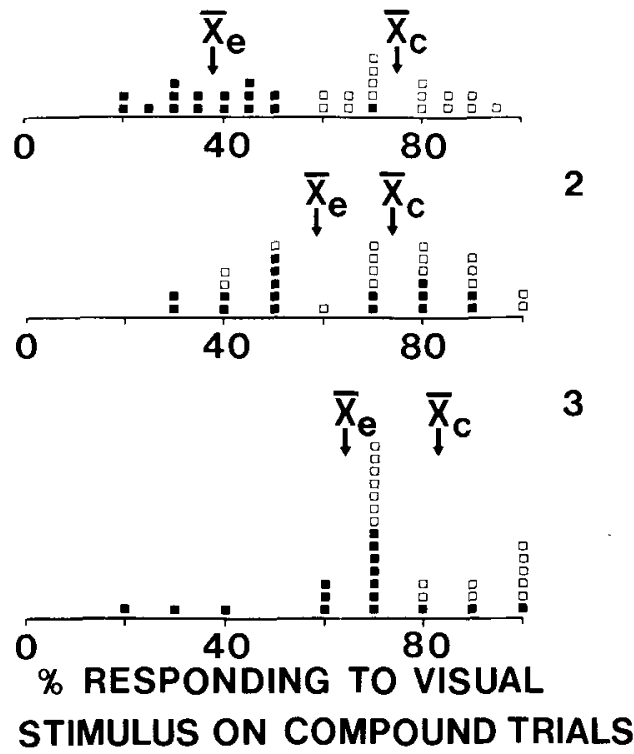

Figure 1. Percent responding on compount trials to the visual stimulus in both the experimental ( $\square$ ) and control ( $\square$ ) groups for each subject. Mean percent responding for each group is also indicated. Panel 1 represents the data from Experiment 1; Panels 2 and 3 represent the data from Experiments 2 and 3, respectively.

\section{Results}

Analysis of variance of percent responding to the visual stimulus revealed a significant main effect of the NS vs. $S$ condition $[F(1,24)=81.83$, $p<.05]$. There were no significant main effects of either sex or response button position. Moreover, there were no significant interactions. Mean percent responses in the NS and S groups to the visual stimulus were 76 and 38, respectively. Percent responding for each subject on compound trials to the visual stimulus in both the experimental and control groups is shown in Figure 1 (Panel 1).

A chi-square analysis revealed that the NS group's responding to the visual stimulus was at a significantly greater than chance level $\left[\chi^{2}(1, N=15)=16.00\right.$, $\mathrm{p}<.05]$. The $\mathrm{S}$ group responded to the visual stim- ulus at a level significantly below that of chance $\left[\chi^{2}\right.$ $(1, \mathrm{~N}=16)=6.25, \mathrm{p}<.05]$.

There were no significant differences between mean auditory and visual RTs in the practice, single, or compound trials for either the NS group or the S group. Mean RTs for each of these groups can be found in Table 1.

\section{Discussion}

The present experiment demonstrates that vision is not the dominant sensory modality in the group receiving electric shock. Although it is important to have demonstrated attenuation to the normally attended visual stimulus, it is perhaps more significant to have reversed the attended modality. In light of the visual dominance experiments previously discussed, and on the basis of the present findings, it is suggested that the normally observed visual dominance found in humans may be limited to nonaversive situations. Since the effects of aversive stimulation have previously not been examined in the human context, it is not surprising that vision has been observed as the usually attended modality.

Several aspects of the situation encountered by the experimental group might be responsible for the reversal of visual dominance. It is important to explore the relative contribution of each of these components before speculating on the underlying mechanism. One explanation for the above findings suggests that a physiological and/or cognitive state of arousal resulting from the presence of aversive electric shock is responsible for the observed attentional shift away from vision and towards audition. Experiment 2 explored the potential contribution of such arousal through fear of shock, and Experiment 3 explored the effects of tactile stimulation without the aversive component of electric shock.

\section{EXPERIMENT 2}

Experiment 2 examined the effect of producing cognitive arousal without the tactile sensation pro-

Table 1

Mean Reaction Time to Auditory and Visual Stimuli on Practice, Single-, and Compound-Stimulus Trials for Control and Experimental Subjects

\begin{tabular}{|c|c|c|c|c|c|c|c|c|c|}
\hline & \multicolumn{3}{|c|}{ Practice } & \multicolumn{3}{|c|}{ Single } & \multicolumn{3}{|c|}{ Compound } \\
\hline & $\mathbf{A}$ & V & $\mathbf{t}$ & $\mathbf{A}$ & $\mathrm{V}$ & $\mathrm{t}$ & A & $\mathbf{V}$ & $\mathrm{t}$ \\
\hline \multicolumn{10}{|c|}{ Experiment 1} \\
\hline $\begin{array}{l}\text { Control } \\
\text { Experimental }\end{array}$ & $\begin{array}{l}420 \\
403\end{array}$ & $\begin{array}{l}378 \\
361\end{array}$ & $\begin{array}{l}1.53 \\
1.55\end{array}$ & $\begin{array}{l}439 \\
449\end{array}$ & $\begin{array}{l}440 \\
432\end{array}$ & $\begin{array}{l}0.02 \\
0.92\end{array}$ & $\begin{array}{l}449 \\
437\end{array}$ & $\begin{array}{l}458 \\
403\end{array}$ & $\begin{array}{l}0.31 \\
1.57\end{array}$ \\
\hline \multicolumn{10}{|c|}{ Experiment 2} \\
\hline $\begin{array}{l}\text { Control } \\
\text { Experimental }\end{array}$ & $\begin{array}{l}446 \\
464\end{array}$ & $\begin{array}{l}374 \\
391\end{array}$ & $\begin{array}{l}4.31^{*} \\
3.70^{*}\end{array}$ & $\begin{array}{l}472 \\
451\end{array}$ & $\begin{array}{l}453 \\
443\end{array}$ & $\begin{array}{l}1.82 \\
0.37\end{array}$ & $\begin{array}{l}427 \\
455\end{array}$ & $\begin{array}{l}449 \\
456\end{array}$ & $\begin{array}{l}0.99 \\
0.04\end{array}$ \\
\hline \multicolumn{10}{|c|}{ Experiment 3} \\
\hline $\begin{array}{l}\text { Control } \\
\text { Experimental }\end{array}$ & $\begin{array}{l}408 \\
457\end{array}$ & $\begin{array}{l}364 \\
412\end{array}$ & $\begin{array}{l}2.40^{*} \\
1.24\end{array}$ & $\begin{array}{l}443 \\
448\end{array}$ & $\begin{array}{l}426 \\
437\end{array}$ & $\begin{array}{l}1.16 \\
0.54\end{array}$ & $\begin{array}{l}402 \\
440\end{array}$ & $\begin{array}{l}400 \\
426\end{array}$ & $\begin{array}{l}0.10 \\
0.54\end{array}$ \\
\hline
\end{tabular}

Note-A = auditory $; V=$ visual. $\quad$ *Significant $t$ values $(p<.05)$ between the above pairs of auditory and visual $R T s$. 
duced by electric shock. It was expected that such a manipulation would attenuate normally observed visual dominance. Experiment 2 presented subjects with the "threat" of an electric shock (established before the experiment began), although no actual shock occurred during the experimental session.

\section{Method}

Subjects. The subjects were 32 right-handed undergraduates who were naive to the present experiment. Since there was no significant effect of either sex or response button position in Experiment 1, these variables were not counterbalanced in Experiment 2. All subjects were recruited and assigned as in Experiment 1.

Apparatus. The apparatus used in Experiment 2 was identical to that used in Experiment 1.

Procedure. The subjects were assigned randomly to either the "shock" ("S") or no-shock (NS) treatment group. Before the experiment began, the subjects in the " $S$ " group set their own shock levels as in Experiment 1. In the first part of the experiment, all subjects received 20 simple RT (practice) trials, as in Experiment 1 . The subjects were informed about which stimulus (tone or light) to expect on each practice trial. The subjects were instructed to respond as in Experiment 1.

Following practice trials, the subjects were presented with a series of "choice" trials, as in Experiment 1. As before, the subjects were not informed about which stimulus would occur. The number of choice trials was reduced in the present experiment from 100 to 90 . The change in total number of trials was due to the reduction in number of compound trials (tone and light presented simultaneously) from 20 to 10 . This reduction in compound trial density was made as a result of the concern in Experiment 1 that the subjects might adopt response strategies, for example, choosing all tones or all lights, if compound trials occurred too frequently.

Subjects in the "S" group were informed that they would receive infrequent shocks throughout the experimental session, but no shocks were ever delivered during the session. In Experiment 1, the subjects were told that a shock would occur if RT was either too fast or too slow. In contrast, the subjects in Experiment 2 were given no rationale for the occurrence of shock. The change in instructions was made to prevent subjects in the present experiment from discovering that, in fact, no shocks were ever to occur. It was believed that subjects were more likely to discover the "deception" in Experiment 2 (given that no shocks ever occurred) than were subjects in Experiment 1, in which shocks were occasionally delivered.

Subjects in the " $S$ " group were given a rest period midway through the choice trials, as in Experiment 1. At this time, the subjects were given "refresher" shocks at the intensity set prior to the experiment to determine if any adjustments were necessary to maintain an "aversive, but not painful" level of shock. The shock intensity was adjusted, if necessary, as in Experiment 1.

All RTs and the stimulus chosen on compound trials were recorded for each subject. Mean auditory and visual RTs on both simple (practice) and choice trials were computed, as was percent responding to both auditory and visual stimuli on compound trials.

\section{Results}

Analysis of variance of percent responding to the visual stimulus revealed a significant treatment effect between the " $S$ " ( mean $=59.4)$ and NS (mean $=73.8)$ groups $[F(1,30)=4.24, p<.05]$. Percent responding for each subject on compound trials to the visual stimulus in both the experimental and control groups is shown in Figure 1 (Panel 2). A chi-square analysis revealed that the NS group responded to the visual stimulus at a significantly greater than chance level $\left[\chi^{2}(1, N=16)=6.25, p<.05\right]$. The " $S$ " group, on the other hand, responded to the visual stimulus at a level significantly below that of chance $\left[\chi^{2}(1, N=16)\right.$ $=4.00, \mathrm{p}<.05]$.

There were no significant differences between mean auditory and visual RTs in either the single or compound trials for either the NS group or the " $S$ " group. There was, however, a significant difference between auditory and visual RTs for both groups during practice trials. Mean RTs for each of these groups can be found in Table 1.

\section{Discussion}

The present experiment demonstrates that a threat of electric shock significantly attenuates visual dominance. Although the difference in visual dominance between the experimental and control groups was only $14.5 \%$, statistical analysis of the data from the experimental group suggests that there is a higher probability of responding to the auditory than to the visual stimulus on compound trials. The group experiencing no threat of electric shock, on the other hand, demonstrated the same visual dominance found in Experiment 1. In Experiment 1, the aversiveness or physiological/cognitive arousal maintained by the actual occurrence of electric shock is believed to be responsible for the observed reversal in sensory dominance. Similarly, in Experiment 2, it appears that the level of arousal produced by the threat, rather than actual occurrence, of shock is also sufficient to produce a reversal in sensory dominance. The contribution of the tactile component of electric shock was investigated in Experiment 3.

\section{EXPERIMENT 3}

The purpose of Experiment 3 was to investigate the relative contribution of a tactile stimulus in attenuating visual dominance. In Experiment 3, the control group was presented with compound tone and light trials embedded in single-stimulus trials, as in Experiments 1 and 2. A second group was treated identically, with the added provision that the subjects received a tactile stimulus on the same trials in which shocks occurred in Experiment 1.

\section{Method}

Subjects. The subjects were 32 right-handed undergraduates who were naive to the present experiment. They were recruited and assigned to either the tactile (experimental) group or no-tactile (control) group.

Apparatus. The tactile stimulus was delivered by three blunt metal prongs, each $1 \mathrm{~mm}$ in diameter. In the resting position, the prongs protruded $2 \mathrm{~mm}$ above a metal plate on which the subject's fingers rested. When the tactile stimulus was delivered, the prongs extended to $7 \mathrm{~mm}$ and then returned immediately to resting posi- 
tion. The tactile device was enclosed in a sound-attenuating metal box and accessed through a rectangular opening. A switch closure automatically initiated by the end of a trial caused an electromagnet to raise the prongs to the extended position. The tactile apparatus was controlled by the same electromechanical equipment used in Experiment 2. All other apparatus was identical to that used in Experiment 2.

Procedure. As in Experiments 1 and 2, Experiment 3 began with each subject's being given 20 simple RT (practice) trials. The subjects were informed which stimulus (tone or light) to expect on each trial, and were instructed to respond as in the previous experiments.

Following the practice trials, the subjects were presented with a series of "choice" trials, as in Experiment 2. As before, the subjects were not informed about which stimulus would occur on "choice" trials. The number of "choice" trials was the same as in Experiment 2.

Subjects in the tactile group were informed that they would receive infrequent tactile stimuli during both practice and "choice" trials. They were then instructed to place the three middle fingers of their left hands on the metal prongs. The tactile stimulus was described to the subjects as being not painful, but no rationale was offered for its occurrence. Tactile stimulation was programmed to occur on the same trials and at the same time (immediately following the response) as shock presentations in Experiment 1. All subjects were given a rest period midway through the "choice" trials, as in Experiment 2. All RTs and the stimulus chosen on compound trials were recorded for each subject. Mean auditory and visual RTs on both practice and "choice" trials were computed, as was percent responding to both auditory and visual stimuli on compound trials.

\section{Results}

Analysis of variance of percent responding to the visual stimulus revealed a significant treatment effect between the tactile (mean $=64.4$ ) and no-tactile $($ mean $=83.1)$ groups $[F(1,30)=10.11, \mathrm{p}<.05]$. Percent responding for each subject on compound trials to the visual stimulus in both the experimental and control groups is shown in Figure 1 (Panel 3). A chisquare analysis resulted in a significantly greater than chance level of responding to the visual stimulus in the group receiving the tactile stimulus $\chi^{2}(1, N=15)$ $=6.25, \mathrm{p}<.05]$ as well as in the no-tactile group $\left[\chi^{2}(1, \mathrm{~N}=16)=16.00, \mathrm{p}<.05\right]$.

There were no significant differences between mean auditory and visual RTs in either the single or compound trials for both the no-tactile and the tactile groups. There was, however, a significant difference between auditory and visual RTs for the notactile group during practice trials. Mean RTs for each of these groups are given in Table 1.

\section{Discussion}

The results of the present experiment demonstrate that the presence of a tactile stimulus significantly attenuates visual dominance. The reduction in visual dominance of the experimental relative to the control group is approximately equal to that found in the threat-of-shock treatment in Experiment 2. Although it might be argued that there is a certain degree of cognitive/physiological arousal maintained by the tactile stimulus in the present experiment, it is un- likely that there is an aversive quality, per se, to the tactile stimulus. The tactile stimulus in Experiment 3 was intended to mimic a weak shock. Thus, the tactile properties of the stimulus in the present experiment were similar to those of Experiment 1. The level of arousal, however, should have been significantly reduced as a consequence of the absence of shock. It was believed that use of a weak shock would have evoked cognitive associations (e.g., fear) and thus defeat the purpose of the experiment.

\section{GENERAL DISCUSSION}

Experiment 1 demonstrates that the presence of noncontingent aversive electric shock causes a shift from normally observed visual dominance to auditory dominance when these two sensory modalities compete for attention. Such a dominance reversal is unusual in light of previous research, which has indicated strong visual dominance over audition, taction, and proprioception in the absence of such shock. Experiments 2 and 3 examined two components of electric shock for their relative contributions to the attentional reversal found in Experiment 1. The results of Experiment 2 indicate that the "cognitive" component of electric shock, threat of shock, causes a significant attenuation of visual dominance, such that the probability of responding to the auditory stimulus is greater than it is to the visual stimulus. Relative to that of controls, responding to the visual stimulus was reduced by $14 \%$. The results of Experiment 3 indicate that the "tactile" component of electric shock also causes attenuation of visual dominance, but that there remains a higher probability of responding to visual than to auditory stimuli. Relative to that of controls, however, responding to the visual stimulus was approximately equally reduced (19\%). It is interesting to note that the sum of the reduction in visual dominance in Experiment 2 (threat of shock) and in Experiment 3 (tactile) approximately equals the reduction in visual dominance of Experiment 1 (actual shock).

The capacity of electric shock to effect a change in attention from vision to audition concurs with the non-sensory (attentional) account offered by Egeth and Sager (1977) and Klein (1977). Egeth and Sager found that certain attentional manipulations, that is, changes in the relative probability of single versus compound-stimulus trials or instructions to attend "hearing," reduced the degree of visual dominance. It seems plausible that such an attentional mechanism is also responsible for the shift from vision to audition in the present experiments. Posner, Nissen, and Klein (1976) have suggested that visual dominance results from a visual attentional bias. The poorer alerting capability of vision relative to audition causes a strategic shift to vision. Such a mechanism appears to operate in most normal circum- 
stances. The present series of experiments thus represents a circumstance in which such a compensatory mechanism seems to be overridden.

The relative degree of visual attenuation in the present series of experiments shows that the experimental groups show less attention to the visual stimulus than do the control groups. Experiments 1 and 2 demonstrate the largest reduction as attention switches from vision to audition, whereas Experiment 3 demonstrates a significant reduction of visual attention. Thus, although it is not clear exactly what mechanism is responsible for the reduced visual attention, it seems likely that some degree of arousal is responsible for the observed effect. It is conceivable that arousal sponsible for the reduced visual attention, it seems likely that some degree of arousal is responsible for the observed effect. It is conceivable that arousal from some other source may also cause a reduction in visual attention. Such arousal, for example, could arise from a subject's viewing a disturbing film or listening to a stimulating speech prior to participation in the experiment. Although it is not possible from the present series of experiments to determine the exact cause of the attentional shift, it is likely that arousal is a contributing factor. In all three experiments, the extra-task "event" (shock, threat of shock, or a tactile stimulus) constituted the only difference between the experimental and the control groups. Since a different amount of visual attenuation resulted from each experimental manipulation, this effect must be due to the specific nature of the event rather than to the simple occurrence of the event, per se.

The outcome of the present experiments is in accord with the findings of the animal learning experiments previously discussed. These experiments found a stimulus-reinforcer interaction such that vision was the dominant stimulus in the appetitive conditioning (positive motivation) groups whereas audition was the dominant stimulus in the aversive conditioning (aversive motivation) group. The present research suggests that, in certain circumstances, it is more adaptive for an organism to attend to auditory rather than visual stimuli. In general, it would seem plausible that such circumstances arise whenever there is a sufficient degree of arousal.

Garcia, McGowan, and Green (1972) have proposed such an evolutionarily derived selective association mechanism as a theoretical account for various stimulus-reinforcer interaction findings reported in the animal learning literature. Under the arousal conditions established in the present experiments, it is conceivable that the non-sensory (atten- tional) mechanism is overridden by the sensory (hard-wired) mechanism favoring the greater alerting capability of audition. This account becomes plausible when one examines the stimulus-to-event relationships encountered in the normal life of a lower organism. Animals engaged in food-seeking behavior obviously must attend to visual stimuli. Conversely, it is clear that, if one considers the relative advantage of the auditory system's 360-deg detection capability over the visual system's more localized detection properties, it is to an animal's advantage in most aversive situations to attend to audition over vision. The present results suggest that such an evolutionarily inherited mechanism may still operate in humans, as well.

\section{REFERENCES}

Colavita, F. B. (1974). Human sensory dominance. Perception \& Psychophysics, 16, 409-412.

Colavita, F. B., \& Weisburg, D. (1979). A further investigation of visual dominance. Perception \& Psychophysics, 25, 345-347.

Egeth, H. E., \& Sager, L. C. (1977). On the locus of visual dominance. Perception \& Psychophysics, 22, 77-86.

Foree, D. D., \& LoLordo, V. M. (1973). Attention in the pigeon: The differential effects of food-getting vs. shock avoidance procedures. Journal of Comparative and Physiological Psychology, 85, 551-558.

Garcia, J., McGowan, B. K., \& Green, K. (1972). Biological constraints on conditioning. In A. H. Black \& W. H. Prokasy (Eds.), Classical conditioning II: Current research and theory (pp. 3-27). New York: Appleton-Century-Crofts.

Gibson, J. J. (1933). Adaptation, after-effect, and contrast in the perception of curved lines. Journal of Experimental Psychology, $16,1-31$.

KLE IN, R. M. (1977). Attention and visual dominance: A chronometric analysis. Journal of Experimental Psychology: Human Perception and Performance, 3, 365-378.

LoLondo, V. M. (1979). Selective associations. In A. Dickinson \& R. A. Boakes (Eds.), Mechanisms of learning and motivation: A memorial to Jerzy Konorsky (pp. 367-399). Hillsdale, NJ: Erlbaum.

Pick, H. L., Warren, D. H., \& Hay, J. C. (1969). Sensory conflict in judgments of spatial direction. Perception \& Psychophysics, 6, 203-205.

Posner, M. I., Nissen, M. J., \& KLein, R. M. (1976). Visual dominance: An information-processing account of its origins and significance. Psychological Review, 83, 157-171.

Randich, A., Klein, R. M., \& LoLondo, V. M. (1978). Visual dominance in the pigeon. Journal of the Experimental Analysis of Behavior, 30, 129-137.

Rock, I., \& Victor, J. (1964). Vision and touch: An experimentally created conflict between the two senses. Science, 143, 594-596.

Shapiro, K. L., Jacobs, W. J., \& LoLondo, V. M. (1980). Stimulus-reinforcer interactions in the pigeon: Implications for selective associations. Animal Learning \& Behavior, 8, 586-594.

(Manuscript recieved January 5, 1984; revision accepted for publication May 8, 1984.) 